\section{Transaction Costs in Planning Literature: A Systematic Review}

\author{
Sina Shahab
}

Journal of Planning Literature

$1-12$

(C) The Author(s) 2021

(c) (i) (5)

Article reuse guidelines: sagepub.com/journals-permissions DOI: 10.1 I77/08854I222II062085 journals.sagepub.com/home/jpl (SSAGE

\begin{abstract}
"Transaction costs," as a well-established theory in New Institutional Economics, has been used to explain and analyze various planning matters for about 30 years since its introduction to planning literature. However, there is no study on how planningrelated studies have utilized the theory. This paper conducts a systematic review that aims to develop a better understanding of how transaction-cost theory is used in planning literature. The review shows that while potential contributions and implications of transaction costs have been conceptually discussed in planning literature, the empirical studies have remained limited, particularly concerning the magnitude of such costs in planning systems.
\end{abstract}

\title{
Keywords
}

transaction costs, planning literature, institutional arrangements, systematic review, urban planning

\section{Introduction}

"Transaction costs" is not a new concept, introduced by Nobel Laureate Ronald Coase in his seminal paper, The Nature of the Firm, in 1937. The concept has been developed by many prominent new institutional economists, such as Williamson (1987, 1989, 1993, 1998, 2003, 2005), North (1992, 1997), and Cheung (1970, 1987). It has several definitions. One of the most commonly used definitions describes transaction costs as all costs involved in a transaction, other than the production costs. This definition parallels Coase's early analysis of "costs of using the price mechanism." People incur such costs in various activities, for example when collecting information, negotiating, contracting, or making payments. Transaction costs arise as a result of bounded rationality of people and uncertainties around transactions. Taking account of transaction costs is particularly important in the context of public policies, as high degrees of transaction costs can lead to reduced levels of policy effectiveness, efficiency, and equity (Coggan et al. 2015; Falconer and Saunders 2002; McCann and Easter 1999; Shahab et al. 2018a, 2018c). High levels of transaction costs can hinder people from participating in a policy instrument, whilst lowering policy efficiency. Also, given transaction costs are often unevenly distributed among actors, their magnitude and distribution have considerable influence on the equity of economic systems.

The introduction of the concept to planning literature is much more recent, compared to other policy-related disciplines. Alexander (1992) paper, A Transaction Cost Theory of Planning, was the first systematic attempt to apply the theories of transaction-cost economics to planning theory. In this paper, he argues that the choice of planning is not a decision related to public intervention. Instead, it is a choice between using either more market mechanisms or more hierarchical organizations and networks. Planning and economics scholars often use welfare economics theory as a theoretical basis and rationale for planning policy intervention (Evans 1974; Moore 1978; Oxley 1975; Walker 1981). Planning, as a form of market intervention, is justified in welfare economics due to the presence of externalities and other market failures. New Institutional Economics, and transaction-cost theory in particular, provide an alternative ${ }^{1}$ to the welfare economics theory in justifying planning interventions (Alexander 2001b; Lai 1994). New Institutional Economics challenges the assumption that externalities and other forms of market failures should be necessarily addressed by direct government intervention into the market. New institutional economists suggest that government might be able to deal with market failures more effectively by creating stronger rights of property to private decision makers and design better institutional arrangements that reduce transaction costs and promote greater certainty within markets. A strong assignment of property rights not only entails clearly defined ownership of all resources, but also clarifies liabilities over externalities (Webster and Lai 2003). Therefore, the assignment of property rights influences the task of internalizing externalities. Defining, exchanging, and enforcing property rights are, however, acts that are accompanied by costs.

There are several examples of transaction costs in the processes of land-use planning, development management, and property development. For example, the time and effort required to find development sites, make development plans,

School of Geography and Planning, Cardiff University, Cardiff, UK

Corresponding Author:

Sina Shahab, School of Geography and Planning, Cardiff University, Cardiff, UK. Email: shahabs@cardiff.ac.uk 
negotiate with landowners and communities, reach agreement between developers and local authorities, review planning applications, and obtain planning permission. These required time and effort can be translated into time-related costs and direct monetary expenses (Coggan et al. 2015; Shahab et al. 2018a), and are incurred by different actors in the process, for example local planning authorities, landowners, or developers. Part of these costs are created to ensure the delivery of highquality developments or environmental enhancement, but it sometimes may be obvious that the costs are excessive, and a process is too lengthy and inefficient. Identifying and reducing such costs helps planners and decision makers to increase the efficiency, effectiveness, and acceptability of their processes (Buitelaar 2007; Sadler and Shahab 2021).

Since its introduction to planning literature, several studies have applied transaction-cost theory to explain and analyze various planning issues (e.g., Darabi and Jalali 2019; Miharia and Woltier 2010; Shahab and Viallon 2019; Staley 2001; Whittington 2012). These include both theoretical and empirical contributions to planning theory and practice. However, to date, there has been a lack of research on how planning scholars have utilized the theory, what implications have been identified from applying the theory to planning issues, what definitions of transaction costs have been used, and what methodological approaches have been applied in planning studies. This paper addresses these questions. Through conducting a systematic review, this paper aims to gain a better understanding of the existing contributions of transaction-cost theory to planning theory and practice, whilst highlighting the areas for future research. To this end, the paper first provides a brief overview of transaction-cost economics. Then, it presents the methodological steps that were undertaken in searching for relevant publications and their analysis. The paper goes on to analyze the use of the theory of transaction costs in planning literature. Finally, the paper presents the discussions and conclusions of this systematic review.

\section{Overview of Transaction-Cost Economics}

"Transaction costs" is one of the central concepts and significant contributions in New Institutional Economics. Although it was conceptually introduced by Ronald Coase (1937) and his article, The Nature of the Firm, where he discussed the costs of using the price mechanism, he had not used the term "transaction cost" until 1970s. The term itself does not appear to have been consciously coined by any particular scholar. There are several definitions of the concept, ranging from "the costs of effecting exchange" (Barzel 1985), "costs of running the economic system" (Arrow 1969), "the cost of exchanging ownership titles" (Demsetz 1969), "the costs of coordinating resources through market arrangements" (Demsetz 1995) to any cost that is convenient and elusive enough to avoid critical examination (Niehans 1987). Allen (1999) identifies two approaches in defining the concept of transaction costs: "neoclassical" and "property rights" definitions. The former refers to the costs of exchanging and trading in the market, whereas the latter definition considers transaction costs as the costs of creating and enforcing property rights. Despite all inconsistencies in the definitions and interpretations of the concept, there is a consensus among transaction-cost economists that these costs have to be distinguished from the production costs, which are the main concern of neo-classical economics (Williamson 1985).

Transaction-cost theory is used to predict which of the three main governance forms of hierarchies, markets, or hybrids would be utilized in organizing economic activities (Hennart 1993; Williamson 1975). The theory explains that when transaction costs are high, internalizing the transaction within a hierarchy is the appropriate decision. Conversely, when transaction costs are low, using the market mechanisms, for example buying the good or service on the market, is the preferred option. The transaction is the unit of analysis in transaction-cost economics. A transaction is a transfer of goods, services, or information across technologically separate interfaces (Williamson 1985). Transactions vary widely, ranging from simple and one-off exchanges to complex and ongoing transactions. They have various attributes (McCann 2013; Mettepenningen et al. 2011; Nilsson 2009). The three main attributes of a transaction in transaction-cost economics are asset specificity (i.e., the degree to which the investments for a transaction are re-deployable to other transactions), uncertainty (i.e., a situation that involves limited information and/ or asymmetric information), and frequency (i.e., the number of transactions that occurs in a period of time). High levels of asset specificity mean that the time and effort invested in a transaction cannot be used in other transactions. Such an attribute leads to increased levels of transaction costs. Similarly, when there are high levels of uncertainties around a transaction, involved parties are required to put more time and effort on completing the transaction, which result in higher degrees of transaction costs. Lastly, frequency has a downward influence on transaction costs. Frequent transactions may reduce uncertainty over the transaction, whilst creating trust between actors involved (Rørstad et al. 2007).

\section{Methodology}

The researcher used two databases of Scopus and Web of Science to select studies in planning literature that use transaction costs in their arguments. These databases are among the largest abstract and citation databases of peer-reviewed literature. The researcher used two databases to ensure the inclusion of all relevant studies, whilst minimizing the risks of searching and indexing errors. The researcher carried out the process of study selection between March 25 and April 7, 2020, involving five steps. The first step was searching the databases to identify transaction-cost related studies in planning literature. For this purpose, the keyword of "TRANSACTION COST*" was used, where a "** indicates that variations on the ending of the word (i.e., transaction costs) were permitted. The researcher used quotation marks to ensure that the phrase is searched for as a whole and not picked apart (i.e., transaction or cost) by the 
search engines. The field codes TITLE-ABS-KEY in Scopus and TOPIC in Web of Science were used. There was no need for adding another keyword for transaction costs as the concept is well-established and does not have an accurate equivalent that is used commonly in the literature. Moreover, lack of using the exact phrase of transaction cost in a study shows that the theories of transaction-cost economics have not being utilized, and thereby it is ineligible for this review.

Searching for planning-related studies is more challenging as planning is broad, interdisciplinary, and connected to several other disciplines (Verweij and Trell 2019) such as transportation, environmental policy, design and architecture, and geography. As this systematic review mostly concerns the literature on land-use planning, the researcher used four relevant keywords of PLANNING, "LAND USE," "LAND POLIC", "LAND DEVELOPMENT." For PLANNING, the researcher did not use quotation marks in order to include different variations of the term (e.g., plan, plans, and planning). Using “*” for LAND POLIC was to ensure its both singular and plural forms (i.e., land policy and land policies) are covered in the search. The researcher merged the search results of these planning-related keywords, using the OR function. This was combined with the transaction-cost search result, using the AND function ${ }^{2}$. These searches yielded a total of 863 and 624 items in Scopus and Web of Science respectively.

The second step was to delimit the scope of investigation based on the year of publication, the type of document, and language. As mentioned previously, the theories of transactioncost economics were first introduced in the planning literature by Alexander's paper in 1992. Therefore, this investigation only included the studies published in 1992 onwards. In terms of the type of document, only peer-reviewed journal articles were included, thereby books, book chapters, and commentaries were excluded. The author is aware of two books that are relevant to this review, including "The Cost of Land Use Decisions: Applying transaction cost economics to planning and development" by Buitelaar (2007) and "Property Rights, Planning and Markets: Managing spontaneous cities" by Webster and Lai (2003). Excluding these books has been offset as the respective authors have published their key contributions in journal articles that have been included in this review. And lastly, the review was limited to English-language publications. This reduced the total items to 637 and 482, respectively, in Scopus and Web of Science.

Given the significant overlap of the search results in the databases, the third step was to remove the articles in common. This was undertaken in EndNote and left a total of 933 items. The next step concerned removing the articles that clearly belonged to other disciplines, such as engineering, IT, management, and other public policies. In the last step, the researcher went through the abstract of all remaining 182 articles and removed the ones that were not entirely within the scope of this review. When decisions could not be made solely based on the abstract, the researcher investigated the entirety of article. In order to be retained, an article had to satisfy two criteria. First, it had to address a planning subject, more specifically land-use planning. Second, it had to use the theories of transaction costs in a systematic manner, rather than solely referring to the concept. This yielded a final selection of 72 journal papers for further analysis. The selected papers have been published in 28 different journals. Land Use Policy with 13 articles, Urban Studies and Planning Theory with seven articles, and Environment and Planning $B$ with five articles are the journals that have published more papers on transaction costs in a planning context than other journals.

\section{Transaction-Cost Studies in Planning Literature}

Compared to other policy-related disciplines, transaction costs theory is relatively little used in the field of planning. However, there has been an increasing number of studies that explore the theory and implications of positive transaction costs in planning contexts. This is shown in Figure 1. The studies related to transaction costs in planning literature can be divided into two main groups. First, the studies that explicitly analyze transaction costs or directly use transaction-cost economics to analyze their identified planning-related issues ( 35 articles). In these studies, "transaction costs" is the main focus of the research. Second, the studies that "transaction costs" is not the key focus of the research, but it has been used in a systematic manner to develop a better understanding of issues in question (37 articles). A considerable part (9 articles or about one forth) of these studies concern the Coase Theorem in the context of planning. These studies discuss transaction costs as a main component of the theorem, along with property rights. The examples of these articles are Lai (1994), Lai and Chau (2019), Lai and Davies (2017), Shahab and Viallon (2020), and Gurran et al. (2018). To make this investigation as comprehensive as possible, this systematic literature review has included both groups, although some parts of the analysis has only been limited to the first group. The remaining of the paper refers to these groups as "TC-Studies" and "TC-related Studies," respectively.

\section{Main Investigated Planning Subjects}

The selected journal articles cover various planning subjects and contributions, as outlined in Table 1. The main two areas of research have been "planning theory" and "policy analysis," comprising more than half of the articles. While the early publications on transaction costs in planning literature were mainly focused on the theoretical contributions of this strand of economics to planning, the recent studies have been mostly concentrated on the empirical aspects of transaction costs, particularly the analysis of planning policy instruments. The contributions to planning theory range from understanding planning as a process of co-ordination (Alexander 1992, 1994, 2001a, 2001b) to articulating and justifying the logic of critical communicative planning (Sager 2006). The studies related to policy analysis address different planning policy instruments, such as Transferable Development Rights (TDR) programs (Hou et al. 2020; Shahab et al. 2018a, 2018b, 


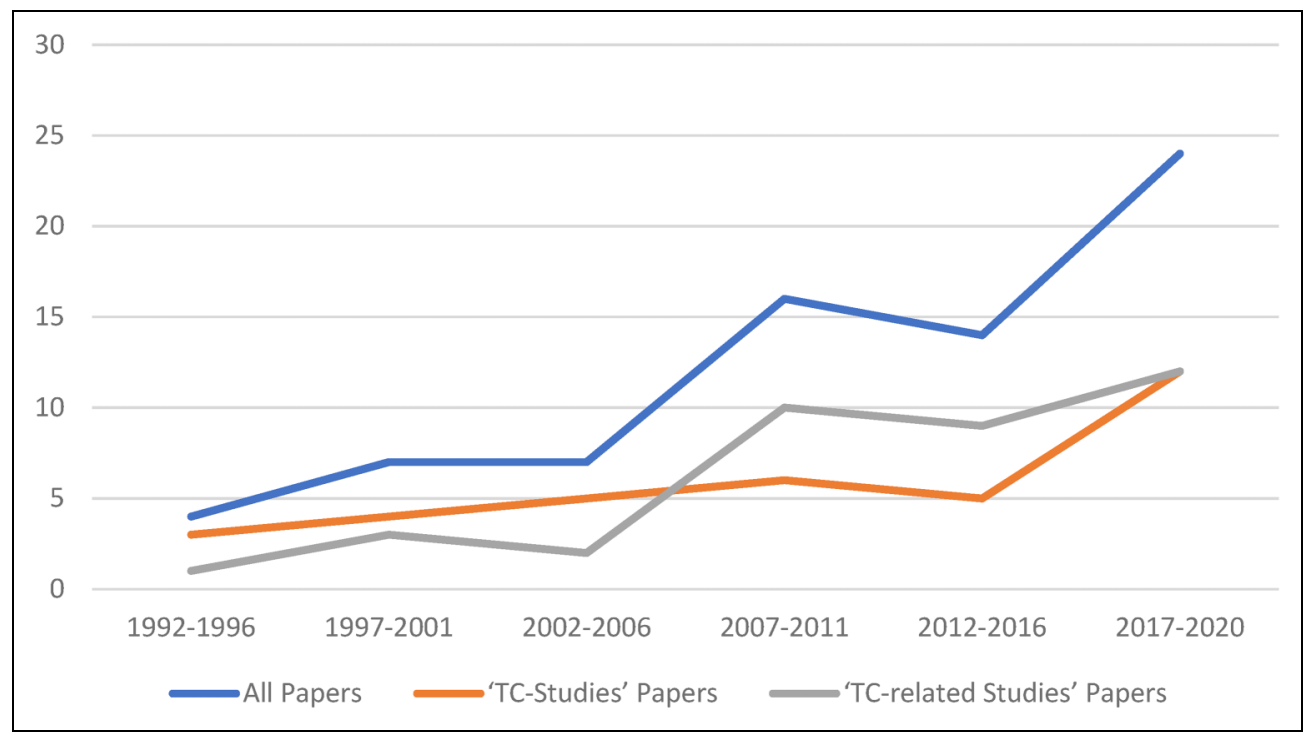

Figure I. Number of articles that studied transaction costs in planning literature over time.

2019), ballot-box zoning (Staley 2001), and land readjustment (Shahab and Viallon 2019). These studies have analyzed different aspects of transaction costs (e.g., their magnitude, timing, and distribution) within the context of a policy instrument and suggested the ways to reduce such costs in order to achieve increased levels of policy effectiveness, efficiency, and equity. Apart from planning theory and policy analysis, other relatively common planning subjects were informal settlements (Darabi and Jalali 2019; Lai and Tang 2016; Yuan et al. 2019), transport (Miharia and Woltier 2010; Sager and Ravlum 2005), infrastructure (Whittington 2012), and property development (Wong et al. 2011). ${ }^{3}$

\section{Utilized Definitions of Transaction Costs}

The concept of transaction costs has various definitions and interpretations within the economics literature. Among the

Table I. Main Subjects in Articles Addressing Transaction Costs in Planning Literature.

\begin{tabular}{lcccccc}
\hline & \multicolumn{2}{c}{ TC-Studies } & & \multicolumn{2}{c}{ TC-related Studies } \\
\cline { 2 - 3 } \cline { 6 - 7 } Main subjects & $\begin{array}{c}\text { No. of } \\
\text { articles }\end{array}$ & $\%$ & & $\begin{array}{c}\text { No. of } \\
\text { articles }\end{array}$ & $\%$ \\
\hline Planning theory & 10 & 28.6 & & 10 & 27.0 \\
Policy analysis & 9 & 25.7 & & 24.3 \\
Informality & 3 & 8.6 & & 4 & 10.8 \\
Housing & 2 & 5.7 & & - & - \\
Transport & 2 & 5.7 & & 5.4 \\
Preservation/ & 2 & 5.7 & & - & - \\
$\quad$ Conservation & 1 & 2.9 & & 3 & 8.1 \\
Infrastructure & 2 & 5.7 & & - & - \\
Regeneration & 1 & 2.9 & & 4 & 10.8 \\
Property development & 3 & 8.6 & & 5 & 13.5 \\
Others & & & & & \\
\hline
\end{tabular}

"TC-Studies" articles, only 13 papers (36 percent) explicitly defined transaction costs in their works. Other studies either did not attempt to define the concept (e.g., Alexander 1992; Curry 2013; Jaffe 1996; Webster 2009) or merely presented some examples of what such costs might include (e.g., Alexander 1994; Cho 2011; Dawkins 2000). Using Allen (1999) classification of the definition of transaction costs, it appears that the "neoclassical" definition has been more commonly utilized in planning literature, compared to the "property rights" definition. This is perhaps because of the higher degree of applicability of this definition, which provides a narrower understanding of transaction costs as opposed to its counterpart. Darabi and Jalali (2019), for example, employed the neoclassical definition in their research, arguing that it offers a narrower scope to address their research objectives. Similarly, Wong et al. (2011) used Cheung's (1970) definition of transaction costs, understanding them as the cost of specifying and measuring the characteristics of what is being exchanged and the cost of enforcing agreements.

\section{Research Approaches and Utilized Methodologies}

"TC-Studies" articles consist of both empirical (19 articles) and nonempirical (16 articles) research. As Figure 2 shows, while the initial contributions were primarily nonempirical, the more recent research on transaction costs in planning literature have moved towards empirical contributions. Empirical studies include the articles that collected and analyzed data in a systematic manner. Nonempirical studies include the papers that aimed at contributing to planning theory (e.g., Buitelaar 2004; Webster 2009), as well as the studies that provided a review of transaction costs and different planning issues (e.g., Dawkins 2000; Musole 2009). There are some studies that included some data as examples to support their arguments (e.g., Alexander 2001a; Lai 2016). These studies were 


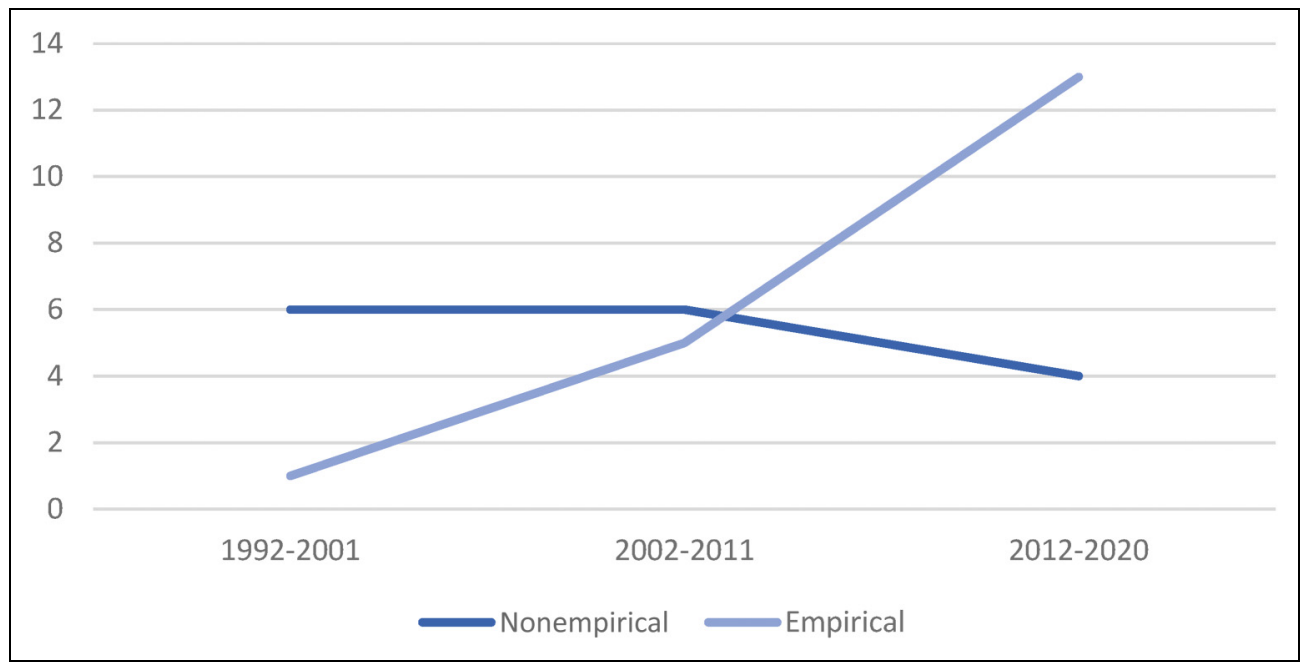

Figure 2. Empirical and nonempirical "TC-Studies" over time.

considered nonempirical in this review, given their overall research approach was not empirical and the presented data were not systematically collected or analyzed.

Among the 35 articles of "TC-Studies" group, 25 papers used a case-study methodology or presented their discussions within a particular context. While most of these empirical studies concentrated their analyses within one geographical/ institutional context (e.g., China, Hong Kong, and United States), only one study attempted to provide a cross-country comparative analysis. Tan and Beckmann (2010) applied a model of transaction-cost economics to analyze different forms of quota systems that have been implemented to preserve farmland within the contexts of four different countries. They examined TDR programs in the United States, command-and-control quotas and their supplemented trading mode in China, agricultural zoning in the Netherlands, and the tradable planning permits for land-use control in Germany.

"TC-Studies" used both primary and secondary data in their analyses, as outlined in Table 2. Interviews are the most common method of collecting primary data in these articles. Hou et al. (2020), for example, conducted interviews with planners and other professionals involved in the process of implementing TDR programs in Hong Kong in order to analyze the transaction costs arising from these programs. "TC-Studies" have also employed surveys to collect data on transaction costs in planning contexts. Curry (2013), for instance, conducted surveys about the transaction costs generated from

Table 2. Types of Data and Methods of Data Collection Used in "TC-Studies."

\begin{tabular}{lcc} 
Data collection & Number of articles \\
\hline Primary data & Interview & 12 \\
& Survey & 3 \\
Secondary data & Q-methodology & 1 \\
\hline
\end{tabular}

decision-making processes over rural space in the county of Gloucestershire in South West England. The survey questions in this study were designed based on a Likert scale, in which respondents could choose from strongly agree to strongly disagree choices. In addition to interviews and surveys, Q-methodology ${ }^{4}$ was utilized in one study to collect and analyze data. Miharia and Woltier (2010) used this method to explore the perception of planning actors on the relationship between Indonesian decentralization and the phenomenon of fragmented local governments with a focus on metropolitan transport planning. Among the "TC-Studies" papers, five articles used secondary data. Lai and Tang (2016), for example, analyzed the institutional barriers to redevelopment of urban villages in Shenzhen, using the secondary data collected from central and local governments' policy documents and databases. Similarly, Darabi and Jalali (2019) used secondary data on the formal development applications and the reports on informal land developments to compare the transaction costs arising from formal and informal developments in Tehran, Iran.

\section{Reported Empirical Results and Findings}

As mentioned in the previous sections, 19 studies among "TC-Studies" articles conducted empirical research. A summary of the empirical results and findings of these studies is presented under the headings of transaction-cost measurements, transaction costs of development management, and the effects of governance and institutional arrangements on transaction costs.

Transaction-Cost Measurements. Even though measuring the magnitude of transaction costs is a complex task, the literature on transaction-cost economics has developed various methodologies to estimate the size of such costs in different contexts. The endeavors to measure transaction costs are rare in planning literature. Only three studies (Darabi and Jalali 2019; Shahab 
et al. 2018a; Whittington 2012) attempted to quantitatively measure the magnitude of transaction costs in planning contexts. Shahab et al. (2018a) estimated that the total transaction costs of implementing TDR programs in four case studies in Maryland range from 13 percent to 21 percent of total TDR costs per transaction. They found out that such transaction costs were mainly borne by private-sector participants (i.e., landowners). Largely because of the market-based nature of TDR programs and transactions, policy administrators were reported to bear fewer transaction costs associated with the administration and information collection activities, compared to those related to the traditional regulatory instruments, such as Purchase of Development Rights and easement programs. They calculated the total transaction costs as a sum of the timerelated costs (i.e., the costs of time spent on each transactional activity) and direct monetary expenses (i.e., all other costs involved in the transaction that are not time-related). Shahab et al. (2018a) concluded that gaining a better understanding of the size of transaction costs in planning policy instruments and their distribution among parties involved can help planners to design and implement such instruments in a more effective, efficient, and equitable manner. Reducing transaction costs of planning processes and policies is important because high transaction costs, on the one hand, can have considerable impact on the efficiency and equity of any policy and, on the other hand, they may discourage people from participating in a policy, thereby reducing the efficacy of the policy itself (Shahab and Lades 2021).

Darabi and Jalali (2019) compared the size of the transaction costs arising from formal and informal development processes. Unlike Shahab et al. (2018a) study which collected primary data using interviews, Darabi and Jalali (2019) used official databases and reports for their estimations of transaction costs. They argued that individual developers of informal settlements carry out some of their development activities in the formal economy to tie them to formal institutions that protect them against enforcement and opportunistic behaviors, whilst completing other activities in the informal economy to avoid the high transaction costs of the formal economy. In short, transaction costs influence decisions about whether activities are carried out in the formal or informal economy.

Whittington (2012) also quantified the levels of transaction costs in order to compare two modes of contracts (i.e., bid-build and design-build contracts) for delivering infrastructure projects. Through exploring two similar road infrastructure projects in the State of Washington, the study showed that the project that used the design-build contract mode saved $\$ 2.8$ million on change orders and disputes, whilst reducing the cost of design by $\$ 400 \mathrm{k}$. However, the author acknowledged that one pair of projects cannot be used to draw conclusions on whether a mode of contract safeguards against opportunistic behaviors and thus curb transaction costs. She concluded that any attempt to evaluate cost-effectiveness in planning processes must take account of both production costs and transaction costs.

In addition to the three articles mentioned above, two studies (Hou et al. 2020; Hu et al. 2019) discussed the magnitude of transaction costs without quantifying such costs in monetary terms. Hu et al. (2019) provided some indications of whether transaction costs are higher or lower in different land renewal policies in Shanghai and Shenzhen, compared to the old landbanking model. However, they did not attempt to quantify or estimate the magnitude of such costs. Similarly, Hou et al. (2020) discussed the size of transaction costs in different stages of implementing TDR programs, using a scale of high, medium, and low.

Transaction Costs of Development Management. Several empirical studies, among the "TC-Studies" articles, analyzed various aspects of development management from the perspective of transaction-cost economics. Wong et al. (2011) investigated the transaction costs in the processes of property development in Hong Kong and argued that such costs are "unpredictable and extremely high." They considered the costs arising from complying with planning regulations as the main transaction costs in these processes. High transaction costs can considerably influence the works of property developers, particularly in the context of Hong Kong where about 60 percent of total project costs are incurred at the beginning of development projects through purchasing land. The main sources of transaction costs are the uncertainties and ambiguities around some of the development management regulations, particularly with regards to planning permissions and their approval and rejection criteria. Also, local authorities often do not clearly and explicitly communicate the development requirements to developers, leaving them to guess or interpret what is required. One of the interviewed surveyors in this study stated that "we spend a lot of time learning by trial and error. That is very timeconsuming." Such uncertainties and ambiguities can delay the delivery of projects and defer developers' investment returns. The authors discussed a number of policy recommendations to reduce transaction costs, for example preparing clear criteria for assessing development applications and enhancing the coordination between the government departments that have responsibilities over the development management processes.

In analyzing TDR programs in four counties in the U.S. state of Maryland, Shahab et al. (2018b) highlighted the importance of timing and distributional considerations of transaction costs arising from designing and implementing these policy instruments of development management. The empirical findings of this study showed that the transaction costs associated with the process of designing and implementing TDR programs, on the one hand, vary across time, and on the other hand, are not distributed evenly among the actors involved in and interacting with the TDR programs. While the costs generated within the policy design stage were mostly incurred by publicsector planners and local authorities, the costs that arose from the implementation stage were largely borne by private parties (i.e., landowners and developers). Shahab et al. (2019), also, analyzed the factors that influence transaction costs in designing and implementing TDR programs. They found out that the factors such as uncertainty around TDR prices and finding buyers/sellers, involvement of 
intermediaries, opportunistic behaviors of involved actors, and the adapted policy approach have considerable influence on the size and distribution of transaction costs. For example, where a bottom-up approach in policy selection and design was employed, the transaction costs of designing the policy instrument were considerably lower, compared to those counties where a top-down approach was used.

Hu et al. (2019) compared the effects of different arrangements and mechanisms of value capture on transaction costs and political legitimacy in urban renewal projects in Shanghai and Shenzhen. After explaining the change from land banking to self-renewal model, as the main approach in urban renewal in China, the authors argued that while this change has greatly reduced negotiation costs, the costs of maintaining the government's legitimacy have been increased. To reduce legitimacy costs, the government has introduced value constraint mechanisms in which the government can add conditions or requirements (e.g., taxation) to new land contracts in renewal projects. However, the use of value constraint mechanisms has increased information and monitoring costs for the government. Hu et al. (2019) concluded that if the total costs of a renewal project, including transaction and legitimacy costs, exceed its benefits, the project will be impeded.

Through an empirical analysis of 63 cities in the US state of Ohio, Staley (2001) found out that subjecting rezoning decisions to public referenda (i.e., popular voting on overturning existing laws or ordinances) has led to the reduced levels of building activity in cities. The research identified the increased levels of uncertainties over the development management process, and consequently higher transaction costs, as the main causes of such reduction in development activities. In other words, while ballot-box zoning (i.e., the process of subjecting land-use decisions to popular vote) broadens citizen participation in local land-use decisions, it discourages property owners and developers to initiate development projects. However, the author highlighted that these findings should not be interpreted as "confirmation that planning always increases transaction costs" (p. 35). In fact, planning can reduce the transaction costs of development projects through identifying and resolving problems at the early stages of development projects, and thereby avoiding potential grassroots opposition that can cause delays. These findings are consistent with Curry (2013) study in which he argued that the increased levels of community involvement have increased the overall costs of decision-making for rural England; however, actors who were involved in decision-making about rural spaces found such costs justifiable given they were spent on activities that allowed them to be better informed.

The Effects of Governance and Institutional Arrangements on Transaction Costs. The types of governance and institutional arrangements have considerable implications for the size and distribution of transaction costs in any systems. These implications have been acknowledged by some of the selected journal articles with regard to planning systems. Yuan et al. (2019), for example, compared the redevelopment of three urban villages in Guangzhou in terms of their institutional arrangements. They identified three forms of institutional arrangements: government-led, developer-led, and partnership. They found out that the choice of institutional arrangements has considerable effects on the levels of transaction costs, and consequently the efficiency and equity of the redevelopment projects. A low degree of agreement between developers and affected villagers can lead to costly and time-consuming redevelopment processes. They suggested the use of information and communications technologies to facilitate communications between villagers and planning authorities and to lower the levels of transaction costs and conflicts in the redevelopment projects in the Chinese urban villages. They also highlighted the importance of engaging with stakeholders and the local communities in order to reduce the transaction costs of redevelopment processes.

Using the theory of transaction cost politics, Sager and Ravlum (2005) explained the institutional arrangements around delegation practices in transport planning in Norway. They discussed that the considerations surrounding transaction costs determine whether members of parliament (i.e., politicians) decide to delegate the decision making about highways to the executive agencies (i.e., Public Roads Administrations wherein planners are represented). When the transaction costs of delegation are less than the transaction costs of policy making through legislative processes, politicians choose to delegate. This trade-off is a result of politicians' limited time and resources. Given these delegations provide planners with more opportunities to influence the decision-making processes, the authors suggest planners to reduce transaction costs of such delegation. Similarly, the empirical research conducted by Tan et al. (2012) showed that transaction-cost considerations play a key role in the choice of governance structures used for farmland conversion in China. They concluded that the considerations of spatial, temporal, and human capital specificity, information uncertainty, and concerns around the administrative control lead to insourcing, whereas the considerations of duration and incentive intensity result in outsourcing. These findings are in line with the arguments of Walker and $\mathrm{Li}$ (2006) on the use of transaction-cost economics in explaining institutional reform in the provision of public services in Hong Kong.

Miharia and Woltier (2010) assessed the transaction costs involved in the more recent decentralized government system in Indonesia and compared them with those within the formerly centralized system. The Decentralization Act 22/1999 paved the way for the emergence of local governments with spatial planning responsibilities, instead of a strong central government that used to maintain a hierarchical spatial planning system. Despite the benefits arising from this reformed structure of government, the authors argued that the transaction costs involved in the decision-making processes within the decentralized system are often higher and can be considered as an adverse effect of decentralization in Indonesia. This is due to the increase in the need for communication, interaction, and information gathering between fragmented local governments. High levels of 
transaction costs reduce the willingness of local governments to collaborate with each other. Miharia and Woltier (2010) suggested the establishment of regional institutions as a way to reduce transaction costs, through enhancing inter-regional coordination and inter-sectoral integration.

Land-use models and theories often assume that the coordination between buyers and sellers of land is achieved only through the price mechanism. Using the theories of transactioncost economics, Needham and de Kam (2004) challenged this assumption and discussed some alternative mechanisms to such coordination, namely imposed rules and mutual trust. The choice of coordinating mechanism depends on the perceived size of transaction costs associated with each mechanism. In other words, actors choose a mechanism that leads to lower levels of transaction costs. The empirical research in this study showed that if there is a network of trust in place, Dutch housing associations choose to acquire land through the mechanism of mutual trust; otherwise, they buy land through the price mechanism. The authors, however, acknowledge that while the theories of transaction-cost economics are proved to be useful in explaining the choice of coordinating mechanisms, they might be difficult to be used as predictive tools.

\section{Summary and Conclusions}

Since the introduction of transaction costs to planning literature by Alexander (1992) paper, A Transaction Cost Theory of Planning, several planning scholars have used the theories of transaction-cost economics to analyze and explain various planning issues. Through systematically reviewing the literature, this paper aims to gain a better understanding of how planning scholars have applied these theories to different planning contexts. A search of two databases of Scopus and Web of Science resulted in 72 journal papers, in which 35 studies explicitly analyzed transaction costs or directly used transaction-cost economics to analyze their identified planningrelated issues. For the other 37 studies, "transaction costs" was not the key focus of the research, but it was used in a systematic manner to develop a better understanding of issues in question. These studies were analyzed in terms of their main planning topics, utilized definitions of transaction costs, research approaches and utilized methodologies, and reported empirical results and findings.

This review showed that the number of studies that explore the theory and implications of positive transaction costs in planning contexts has been considerably increasing over the last few years. This shows a relatively higher level of awareness and acknowledgement of such hidden costs in planning systems among planning scholars. The contributions in this regard have moved from mostly theoretical studies to more empirical research over the years. While the early contributions were largely nonempirical, the more recent research have explored transaction costs in different contexts from more practical and empirical aspects. In other words, the initial contributions discussed the potential of the theories of transaction-cost economics in explaining planning issues, but more recent studies have taken it further and investigated what the implications of these theories are for planning practice and policy making.

The transaction-cost studies in planning literature have covered a wide range of topics. The main areas of research have been planning theory and policy analysis, followed by informality, housing, and transport. The review also showed that the "neoclassical" definition of transaction costs has been the most commonly used definition of these costs in planning literature. According to this definition, transaction costs refer to the costs of exchanging and trading in the market. The use of the alternative definition, the "property rights" definition, which refers to such costs as the costs of creating and enforcing property rights has been less common. This is perhaps because of the more practical and wider scope of the "neoclassical" definition that allows planning scholars to apply the theories of transaction costs to planning issues and policies.

The methodological approaches and research methods used in planning literature are consistent with transaction-cost studies in other policy-related fields. Most articles utilized a case-study methodology and/or presented their discussions within a geographical/institutional context. In terms of the datacollection methods, interviews by far have been the most popular method. Interviews offer a high degree of flexibility and provide planning researchers with opportunities to probe deeper and unearth the hidden costs generated in planning systems. Where official databases and existing data were available, this data was used by planning scholars as proxies for or indications of transaction costs. Survey was also among the data-collection methods used in these studies. This is in line with the research methods used in the study of transaction costs in other disciplines.

Empirical research on transaction costs in planning contexts have resulted in various findings. The studies concerning development management showed how high levels of transaction costs can act as barriers to realizing development proposals and how decision makers can lower such costs through reducing uncertainties surrounding planning processes and providing clear and sufficient information to actors. While public engagement in decision-making processes has several benefits, the studies showed that such engagements are not costless. They not only may increase the direct monetary and time-related costs of decision-making processes, but also can increase the levels of uncertainties for property developers. Taking account of the views of local residents at the earlier stages of development projects can, however, help managing the uncertainties and reducing transaction costs of the later stages of development process. Similarly in the context of planning policy-making process, while public participation may increase the transaction costs of "policy design," it can reduce the costs of "policy implementation" through increasing the credibility and acceptability of a policy, raising public awareness, and building trust among parties involved.

The empirical studies also showed how decision makers choose certain forms of governance or institutional 
arrangements based on the transaction costs associated with them. In other words, they compare the size and distribution of transaction costs that may generate from different arrangements and choose an arrangement that has the lowest level and/or the most equitable distribution of such costs. Last but not least, this review found out that there are very limited studies concerning the magnitude of transaction costs in planning literature. "What gets measured gets managed" is a wellknown adage in the business world. The same logic applies to planning matters. One of the key steps for planners and decision makers to reduce (or manage) transaction costs associated with their planning decisions is to gain a better understanding of the magnitude of such costs through measuring or estimating them. While there has been an increasing number of empirical studies on transaction costs in planning literature, more work will need to be carried out to determine how these hidden costs affect planning practice and policy making in different contexts (e.g., formal vs. informal, developing vs. developed countries, decentralized vs. centralized governance, and regulatory vs. discretionary planning systems).

\section{Acknowledgments}

The author would like to thank Jonathan Jones, the Subject Librarian of the School of Geography and Planning at Cardiff University, for his advice on the search process.

\section{Declaration of Conflicting Interests}

The authors declared no potential conflicts of interest with respect to the research, authorship, and/or publication of this article.

\section{Funding}

The authors received no financial support for the research, authorship and/or publication of this article.

\section{ORCID iD}

Sina Shahab (iD https://orcid.org/0000-0003-3788-2564

\section{Notes}

1. It is worth noting that there are various arguments in justifying planning interventions, for example, see Campbell and Marshall (2002) and Klosterman (1985).

2. The combined search query was: "Transaction cost*" AND (Planning OR "Land use" OR "Land polic*" OR "Land development").

3. It is worth noting that a paper might have addressed several concepts and issues, the effort here was to identify the main single subject in each paper.

4. Q-methodology is a research method used in humanities and social sciences to study the subjective views of people. Combining qualitative and quantitative methods, Q-methodology requires research participants to make considered decisions and choices between a number of statements. They do this through sorting statements on a topic into order of preference on a grid with the shape of a normal distribution. The collected data then are analysed through correlation and factor analysis. For more information on Q-methodology, see Herrington and Coogan (2011).

\section{References}

Alexander, E. R. 1992. "A Transaction Cost Theory of Planning." Journal of the American Planning Association 58: 190-200. https://doi.org/10.1080/01944369208975793.

Alexander, E. R. 1994. "To Plan or Not to Plan, That Is the Question: Transaction Cost Theory and Its Implications for Planning." Environment and Planning B: Planning and Design 21: 341-52. https://doi.org/10.1068/b210341.

Alexander, E. R. 2001a. "Governance and Transaction Costs in Planning Systems: A Conceptual Framework for Institutional Analysis of Land-Use Planning and Development Control - The Case of Israel." Environment and Planning B: Planning and Design 28: 755-76. https://doi.org/10.1068/b2759.

Alexander, E. R. 2001b. "A Transaction-Cost Theory of Land use Planning and Development Control Toward the Institutional Analysis of Public Planning." Town Planning Review 72: 45-75. https://www.jstor.org/stable/40111825.

Allen, D. W. 1999. "Transaction Costs." In Encyclopedia of Law and Economics, edited by B. Bouckaert, and G. De Geest, 234-239. Cheltenham: Edward Elgar.

Arrow, K. 1969. "The organization of economic activity: issues pertinent to the choice of market versus nonmarket allocation." The Analysis and Evaluation of Public Expenditure: The PPB System, Washington DC: US Government Printing Office.

Barzel, Y. 1985. "Transaction Costs: Are They Just Costs?" Zeitschrift für die gesamte Staatswissenschaft / Journal of Institutional and Theoretical Economics 141: 4-16. https://www.jstor.org/stable/ 40750776.

Buitelaar, E. 2004. "A Transaction-Cost Analysis of the Land Development Process.” Urban Studies 41: 2539-53. https://doi. org/10.1080/0042098042000294556.

Buitelaar, E. 2007. The Cost of Land Use Decisions: Applying Transaction Cost Economics to Planning and Development. Oxford, UK: Blackwell Publishing.

Campbell, H., and R Marshall. 2002. "Utilitarianism's Bad Breath? A Re-Evaluation of the Public Interest Justification for Planning." Planning Theory 1:163-87. https://doi.org/10.1177/ 147309520200100205.

Cheung, S. N. S. 1970. "The Structure of a Contract and the Theory of a Non-Exclusive Resource." Journal of Law and Economics 13: 49-70. https://www.jstor.org/stable/724838.

Cheung, S. N. S. 1987. "Economic Organization and Transaction Costs." In The New Palgrave: A Dictionary of Economics, edited by J. Eatwell, M. Milgate, and P. Newman, 378-384. London: Palgrave Macmillan.

Cho, C.-J. 2011. "An Analysis of the Housing Redevelopment Process in Korea Through the Lens of the Transaction Cost Framework." Urban Studies 48: 1477-501. https://doi.org/10.1177/0042098010375324.

Coase, R. H. 1937. "The Nature of the Firm.” Economica 4: 386-405. https://doi.org/10.1111/j.1468-0335.1937.tb00002.x.

Coggan, A., M. Van Grieken, A. Boullier, and X. Jardi. 2015. "Private Transaction Costs of Participation in Water Quality Improvement Programs for Australia's Great Barrier Reef: Extent, Causes and Policy Implications." Australian Journal of Agricultural and Resource Economics 59: 499-517. https://doi.org/10.1111/14678489.12077 . 
Curry, N. 2013. "Planning and Policy Documents as Transactions Costs: The Case of Rural Decision-Making in England." Land Use Policy 30: 711-8. http://dx.doi.org/10.1016/j.landusepol. 2012.05.017.

Darabi, H., and D. Jalali. 2019. "Illuminating the Formal-Informal Dichotomy in Land Development on the Basis of Transaction Cost Theory." Planning Theory 18: 100-21. https://doi.org/10. $1177 / 1473095218779111$.

Dawkins, C. J. 2000. "Transaction Costs and the Land Use Planning Process." Journal of Planning Literature 14: 507-18. https://doi. org/10.1177/08854120022092809.

Demsetz, H. 1969. "Information and Efficiency: Another Viewpoint." Journal of Law and Economics 12: 1-22. https://www.jstor.org/ stable/724977.

Demsetz, H. 1995. The Economics of the Business Firm. Cambridge: Cambridge University Press.

Evans, A. W. 1974. "Economics and Planning." In Studies in Social Science and Planning, edited by J. Forbes. Edinburgh: Scottish Academic Press.

Falconer, K., and C. Saunders. 2002. "Transaction Costs for SSSIs and Policy Design." Land Use Policy 19: 157-66. https://doi.org/10. 1016/S0264-8377(02)00007-8.

Gurran, N., G. Searle, and P. Phibbs. 2018. "Urban Planning in the Age of Airbnb: Coase, Property Rights, and Spatial Regulation.” Urban Policy and Research 36: 399-416. https://doi.org/10.1080/ 08111146.2018 .1460268$.

Hennart, J.-F. 1993. "Explaining the Swollen Middle: Why Most Transactions Are a Mix of "Market" and "Hierarchy"." Organization Science 4: 529-47. https://www.jstor.org/stable/ 2635079.

Herrington, N., and J. Coogan. 2011. "Q Methodology: An Overview." Research in Teacher Education 1: 24-8. https://doi.org/10.15123/ uel.8604v.

Hou, J., D. Gu, S. Shahab, and E. H.-W. Chan. 2020. "Implementation Analysis of Transfer of Development Rights for Conserving Privately Owned Built Heritage in Hong Kong: A Transactions Costs Perspective." Growth and Change 51: 530-50. https://doi. org/10.1111/grow.12350.

Hu, Y. J., B. Lu, and J. Y. Wu. 2019. "Value Capture in Industrial Land Renewal Under the Public Leasehold System: A Policy Comparison in China." Land Use Policy 84: 59-69. https://doi. org/10.1016/j.landusepol.2019.02.038.

Jaffe, A. J. 1996. "On the Role of Transaction Costs and Property Rights in Housing Markets. Housing Studies 11: 425-34. https:// doi.org/10.1080/02673039608720866.

Klosterman, R. E. 1985. “Arguments for and Against Planning." Town Planning Review 56: 5. https://www.jstor.org/stable/40112168 .

Lai, L. W. C. 1994. "The Economics of Land-Use Zoning: A Literature Review and Analysis of the Work of Coase." The Town Planning Review 65: 77-98. https://www.jstor.org/stable/40113262.

Lai, L. W. C. 2016. "The Redevelopment of Bus Depots: A Transaction Cost Economic Analysis of a Change in the Use of Land in Hong Kong." Planning Practice and Research 31: 80-98.

Lai, L. W. C., and K. W. Chau. 2019. "A Reinterpretation of Coase's Land Monopoly Model: Locational Specificity and the Betterment Potential of Land as de Jure and de Facto Property." Progress in
Planning 131: 1-15. https://doi.org/10.1016/j.progress.2018.01. 002.

Lai, L. W. C., and S. N. G. Davies. 2017. “A Coasian Boundary Inquiry on Zoning and Property Rights: Lot and Zone Boundaries and Transaction Costs." Progress in Planning 118: 1-28. https:// doi.org/10.1016/j.progress.2016.05.001.

Lai, Y., and B. Tang. 2016. "Institutional Barriers to Redevelopment of Urban Villages in China: A Transaction Cost Perspective." Land Use Policy 58: 482-90. https://doi.org/10.1016/j.landusepol.2016. 08.009 .

Mccann, L. 2013. "Transaction Costs and Environmental Policy Design.” Ecological Economics 88: 253-62. https://doi.org/10. 1016/j.ecolecon.2012.12.012.

Mccann, L., and K. W. Easter. 1999. "Transaction Costs of Policies to Reduce Agricultural Phosphorous Pollution in the Minnesota River." Land Economics 75: 402-14. https://doi.org/10.2307/ 3147186

Mettepenningen, E., V. Beckmann, and J. Eggers. 2011. "Public Transaction Costs of Agri-Environmental Schemes and Their Determinants-Analysing Stakeholders' Involvement and Perceptions." Ecological Economics 70: 641-50. https://doi.org/ 10.1016/j.ecolecon.2010.10.007.

Miharia, M., and J. Woltier. 2010. "Interlocal Government Collaboration and Perceived Transaction Costs in Indonesian Metropolitan Transport Planning." International Development Planning Review 32: 167-89. https://doi.org/10.3828/idpr.2010.03.

Moore, T. 1978. "Why Allow Planners to Do What They Do? A Justification from Economic Theory." Journal of the American Institute of Planners 44: 387-98. https://doi.org/10.1080/ 01944367808976917.

Musole, M. 2009. "Property Rights, Transaction Costs and Institutional Change: Conceptual Framework and Literature Review." Progress in Planning 71: 43-85. https://doi.org/10. 1016/j.progress.2008.09.002.

Needham, B., and G. De Kam. 2004. "Understanding How Land is Exchanged: Co-Ordination Mechanisms and Transaction Costs." Urban Studies 41: 2061-76. https://doi.org/10.1080/ 0042098042000256387.

Niehans, J. 1987. "Transaction Costs." In The New Palgrave: A Dictionary of Economics, edited by J. Eatwell, M. Milgate, and P. Newman, 456-462. London: Macmillan.

Nilsson, F. O. L. 2009. "Transaction Costs and Agri-Environmental Policy Measures: Are Preferences Influencing Policy Implementation?" Journal of Environmental Planning and Management 52: 757-75. https://doi.org/10.1080/ 09640560903083723.

North, D. C. 1992. Transaction Costs, Institutions, and Economic Performance. San Francisco, CA: ICS Press.

North, D. C. 1997. "Transaction Costs Through Time.” In Transaction Cost Economics: Recent Developments, edited by C. Menard, 149161. Cheltenham, UK: Edward Elgar Publishing.

Oxley, M. J. 1975. "Economic Theory and Urban Planning." Environment and Planning A 7: 497-508. https://doi.org/10.1068/ a070497.

Rørstad, P. K., A. Vatn, and V. Kvakkestad. 2007. "Why Do Transaction Costs of Agricultural Policies Vary?" Agricultural 
Economics 36: 1-11. https://doi.org/10.1111/j.1574-0862.2007. 00172.x.

Sadler, G., and S. Shahab. 2021. "Self-Build and Custom Housebuilding Registers in England: A Transaction-Cost and Effectiveness Analysis." Sustainability 13. https://doi.org/10. 3390/su13094912.

Sager, T. 2006. "The Logic of Critical Communicative Planning: Transaction Cost Alteration." Planning Theory 5: 223-54. https:// doi.org/10.1177/1473095206068629.

Sager, T., and I.-A. Ravlum. 2005. "From Projects to Strategies: A Transaction Cost Approach to Politicians' Problems with Strategic Transport Planning." Planning Theory \& Practice 6: 213-32. https://doi.org/10.1080/14649350500137077.

Shahab, S., J. P. Clinch, and E. O'neill. 2019. “An Analysis of the Factors Influencing Transaction Costs in Transferable Development Rights Programmes.” Ecological Economics 156: 409-19. https:// doi.org/10.1016/j.ecolecon.2018.05.018.

Shahab, S., J. P. Clinch, and E. O'neill. 2018c. "Accounting for Transaction Costs in Planning Policy Evaluation." Land Use Policy 70: 263-72. https://doi.org/10.1016/j.landusepol.2017.09. 028.

Shahab, S., J. P. Clinch, and E. O'neill. 2018a. "Estimates of Transaction Costs in Transfer of Development Rights Programs." Journal of the American Planning Association 84: 61-75. https://doi.org/10.1080/01944363.2017.1406816.

Shahab, S., J. P. Clinch, and E. O'neill. 2018b. “Timing and Distributional Aspects of Transaction Costs in Transferable Development Rights Programmes." Habitat International 75: 1318. https://doi.org/10.1016/j.habitatint.2018.03.006.

Shahab, S., and L. K. Lades. 2021. "Sludge and Transaction Costs." Behavioural Public Policy 1-22. https://doi.org/10.1017/bpp. 2021.12.

Shahab, S., and F.-X. Viallon. 2019. "A Transaction-Cost Analysis of Swiss Land Improvement Syndicates.” Town Planning Review 90: 545-65. https://doi.org/10.3828/tpr.2019.34.

Shahab, S., and F.-X. Viallon. 2020. "Swiss Land Improvement Syndicates: 'Impure' Coasian Solutions?" Planning Theory 20: 44-62. https://doi.org/10.1177/1473095220923629.

Staley, S. R. 2001. "Ballot-Box Zoning, Transaction Costs, and Urban Growth." Journal of the American Planning Association 67: 25-37. https://doi.org/10.1080/01944360108976353.

Tan, R., and V. Beckmann. 2010. "Diversity of Practical Quota Systems for Farmland Preservation: A Multicountry Comparison and Analysis." Environment and Planning C: Government and Policy 28: 211-24. https://doi.org/10.1068/c09174.

Tan, R., V. Beckmann, F. Qu, and C. Wu. 2012. "Governing Farmland Conversion for Urban Development from the Perspective of Transaction Cost Economics." Urban Studies 49: 2265-83. https://doi.org/10.1177/0042098011423564.

Verweij, S., and E.-M. Trell. 2019. "Qualitative Comparative Analysis (QCA) in Spatial Planning Research and Related Disciplines: A Systematic Literature Review of Applications." Journal of Planning Literature 34: 300-17. https://doi.org/10.1177/ 0885412219841490.

Walker, B. 1981. Welfare Economics and Urban Problems. London: Hutchinson and Co.
Walker, R. M., and L. H. Li. 2006. "Institutional Reform in the Provision of Public Services in Hong Kong: An Efficiency Evaluation." Environment and Planning C: Government and Policy 24: 597-614. https://doi.org/10.1068/c52m.

Webster, C. J. 2009. “Are Some Planning Transactions Intrinsically Sovereign?" Journal of Planning Education and Research 28: 476-90. https://doi.org/10.1177/0739456X08330977.

Webster, C. J., and L. W. C. Lai. 2003. Property Rights, Planning and Markets: Managing Spontaneous Cities. Cheltenham and Northampton: Edward Elgar.

Whittington, J. 2012. "When to Partner for Public Infrastructure?: Transaction Cost Evaluation of Design-Build Delivery." Journal of the American Planning Association 78: 269-85. https://doi. org/10.1080/01944363.2012.715510.

Williamson, O. E. 1975. Markets and Hierarchies, Analysis and Antitrust Implications: A Study in the Economics of Internal Organization. New York: The Free Press.

Williamson, O. E. 1985. The Economic Institutions of Capitalism. New York: Free Press.

Williamson, O. E. 1987. "Transaction Cost Economics." Journal of Economic Behavior \& Organization 8: 617-25. https://doi.org/ 10.1016/0167-2681(87)90038-2.

Williamson, O. E. 1989. "Transaction Cost Economics.” In Handbook of Industrial Organization, edited by R. Schmalesee, and R. Willig. New York: North Holland.

Williamson, O. E. 1993. "Opportunism and its Critics." Managerial and Decision Economics 14: 97-107. https://doi.org/10.1002/ mde.4090140203.

Williamson, O. E. 1998. “Transaction Cost Economics: How It Works; Where It is Headed." De Economist 146: 23-58. https://doi.org/10. 1023/A:1003263908567.

Williamson, O. E. 2003. "Transaction Cost Economics and Agriculture: An Excursion." In Role of Institutions in Rural Policies and Agricultural Markets, edited by G. Van Huylenbroeck, W. Verbeke, and L. Lauwers, 19-39. Amsterdam: Elsevier.

Williamson, O. E. 2005. “Transaction Cost Economics.” In Handbook of New Institutional Economics, edited by C. Ménard, and M. M. Shirley. Berlin: Springer.

Wong, F. W. H., E. H. W. Chan, and A. T. W. Yu. 2011. "Property Developers' major Cost Concerns Arising from Planning Regulations Under a High Land-Price Policy." Journal of Urban Planning and Development 137: 112-20. https://doi.org/10.1061/ (ASCE)UP.1943-5444.0000046.

Yuan, D. H., Y. Yau, H. J. Bao, Y. S. Liu, and T. Liu. 2019. “Anatomizing the Institutional Arrangements of Urban Village Redevelopment: Case Studies in Guangzhou, China." Sustainability 11: 16. https://doi.org/ 10.3390/su11123376.

\section{Author Biography}

Dr Sina Shahab is a Lecturer in Planning and Environmental Policy in the School of Geography and Planning at Cardiff University where he is leading the Spatial Planning and City Environments (SPACE) Research Group. He is also a Representative of the UK planning schools in the Association of European Schools of Planning 
(AESOP). His research interests, experiences, and expertise concern policy analysis, in particular land and environmental policies. Informed by various economic theories, including new institutional economics and behavioural economics, his research explores the ways in which decision-makers can design and implement policies that are more effective, efficient, and equitable. 